\title{
Theoretical insights into selective electrochemical conversion of carbon dioxide
}

\author{
Chan Woo Lee ${ }^{1,2 \dagger}$, Chanyeon Kim ${ }^{1+}$ and Byoung Koun Min ${ }^{1,3^{*}}$
}

\begin{abstract}
Electrochemical conversion of $\mathrm{CO}_{2}$ and water to valuable chemicals and fuels is one of the promising alternatives to replace fossil fuel-based processes in realizing a carbon-neutral cycle. For practical application of such technologies, suppressing hydrogen evolution reaction and facilitating the activation of stable $\mathrm{CO}_{2}$ molecules still remain major challenges. Furthermore, high production selectivity toward high-value chemicals such as ethylene, ethanol, and even $n$-propanol is also not easy task to achieve. To settle these challenges, deeper understanding on underlying basis of reactions such as how intermediate binding affinities can be engineered at catalyst surfaces need to be discussed. In this review, we briefly outline recent strategies to modulate the binding energies of key intermediates for $\mathrm{CO}_{2}$ reduction reactions, based on theoretical insights from density functional theory calculation studies. In addition, important design principles of catalysts and electrolytes are also provided, which would contribute to the development of highly active catalysts for $\mathrm{CO}_{2}$ electroreduction.
\end{abstract}

Keywords: Electrocatalysis, $\mathrm{CO}_{2}$ reduction, Intermediate binding energy, Theoretical calculation

\section{Introduction}

Climate change due to greenhouse gases has been a critical issue that must be solved for human being's sustainable life [1]. Indiscriminate exploitation of fossil fuel has accelerated the global warming issue associated with greenhouse gas emission [2], therefore, clean energy generation technologies should be developed to mostly or partly replace the fossil fuel-based processes. Electrochemically converting $\mathrm{CO}_{2}$ and water to valuable chemicals and fuels, using renewable energy resources such as solar energy, has been one of the promising strategies to realize carbon-neutral energy cycle $[3,4]$. It can generate a variety of products including $\mathrm{HCOOH}, \mathrm{CO}, \mathrm{CH}_{4}$, $\mathrm{C}_{2} \mathrm{H}_{4}, \mathrm{C}_{2} \mathrm{H}_{5} \mathrm{OH}$, and even $\mathrm{C}_{3}-\mathrm{C}_{4}$ chemicals under ambient conditions in a sustainable fashion [5-9]. However, for practical implementation of the electrochemical $\mathrm{CO}_{2}$ conversion technology, suppressing hydrogen evolution reactions (HER) and enhancing selectivity for specific products remain challenges. In general, the HER, a

\footnotetext{
*Correspondence: bkmin@kist.re.kr

${ }^{\dagger}$ Chan Woo Lee and Chanyeon Kim contributed equally to this work ${ }^{1}$ Clean Energy Research Center, Korea Institute Science and Technology, Seoul 02792, Republic of Korea

Full list of author information is available at the end of the article
}

proton reduction reaction, easily occurs as a competing reaction of $\mathrm{CO}_{2}$ reduction reactions $\left(\mathrm{CO}_{2} \mathrm{RR}\right)$ because it is kinetically more facile [10]. In addition, the $\mathrm{CO}_{2}$ can be reduced to various intermediates and products via multiple reaction pathways, resulting in poor selectivity of the reaction [6].

In the electrochemical reaction system, product selectivity of $\mathrm{CO}_{2} \mathrm{RR}$ is deeply associated with the binding affinity of reaction intermediates on the catalyst surface. In specific, polycrystalline $\mathrm{Au}, \mathrm{Ag}$ and $\mathrm{Zn}$ electrodes can evolve $\mathrm{CO}$ with high selectivity because these metals intrinsically possess low binding affinities for an adsorbed "CO intermediate [10-15]. In contrast, Pt, Ni, and $\mathrm{Fe}$ electrodes are poisoned by " $\mathrm{CO}$ owing to their strong binding affinities for "CO [16]. As a result, HER proceeds with high selectivity over $\mathrm{CO}_{2} \mathrm{RR}$. Meanwhile, high selectivity for $\mathrm{HCOO}^{-}$production have been shown from the metals like $\mathrm{Sn}, \mathrm{Pb}$ and $\mathrm{Bi}$ that relatively favor "OCHO over " $\mathrm{COOH} \mathrm{[17-19].} \mathrm{Therefore,} \mathrm{engineering}$ or controlling binding affinities of key intermediates is a critical issue in the product selectivity enhancement.

Recently, effective strategies to tune intermediate binding affinities have been suggested and demonstrated by several pioneering works. Representatively, it was 
reported that electrochemically reduced $\mathrm{Cu}$ oxides possess subsurface oxygens near the catalyst surface, which can increase the "CO binding affinity because the oxygens withdraw electrons from the $\mathrm{Cu}$ sp-band and reduce the $\sigma$-repulsion between a $\mathrm{Cu}$ atom and " $\mathrm{CO}$ molecule [20]. As a consequence, $\mathrm{C}-\mathrm{C}$ coupling reactions by $\mathrm{CO}$ dimerization at the catalyst surface with high $\mathrm{CO}$ coverage can be kinetically promoted. Such a stronger CO binding through subsurface oxygens was also theoretically rationalized in Ag case [21]. In addition, it has been suggested that nanoneedle morphology can enhance electric field at the tip of nanostructure, thereby the alkali metal ions can be concentrated [22]. The solvated alkali metal cations selectively stabilize the polarizable intermediates like ${ }^{*} \mathrm{CO}_{2}$, "CO, "OCCO and "OCCHO due to the electrostatic interactions while " $\mathrm{H}$ is insensitive to the cations due to negligible polarizability [23]. As a result, higher $\mathrm{CO}_{2} \mathrm{RR}$ selectivity could be achieved.

Here, we first address intrinsic limitations of conventional pure metals in terms of binding affinity and product selectivity. Then, we review recent strategies to allow for the binding affinity modulation of $\mathrm{CO}_{2}$ reduction intermediates. The strategies are classified into five groups: (1) oxygen incorporation, (2) electrolyte engineering, (3) nanostructuring, (4) introducing surface ligands, and (5) single-atom catalyst. In each subject, we cover theoretical insights into how the modifications can induce the tuning of binding affinity based on density functional theory (DFT) calculation studies. This review provides important design principles of electrocatalysts to promote $\mathrm{CO}_{2} \mathrm{RR}$ over HER, as well as $\mathrm{C}-\mathrm{C}$ coupling via $\mathrm{CO}$ dimerization pathway.

\section{Challenges of electrochemical $\mathrm{CO}_{2}$ reduction reactions}

$\mathrm{CO}_{2}$ is a stable molecule $\left(\Delta \mathrm{G}_{\mathrm{f}}=-394.4 \mathrm{~kJ} / \mathrm{mol}\right)$ that has electrophilic carbon center due to neighboring oxygen atoms with a linear configuration. The one-electron transfer to $\mathrm{CO}_{2}$ to form the $\mathrm{CO}_{2}{ }^{-}$anion, an initially created intermediate in most cases, requires a very negative potential of $-1.9 \mathrm{~V}$ vs. SHE in a neutral aqueous solution (Table 1) [24]. This thermodynamic limitation makes the overpotential for $\mathrm{CO}_{2} \mathrm{RR}$ much larger than HER, leading to low selectivity for $\mathrm{CO}_{2} \mathrm{RR}$. Furthermore, although the $\mathrm{CO}_{2}$ molecule can be activated at more favorable overpotentials by the concerted proton-electron transfer pathway or the promotional effect of alkali metal cations contained in electrolytes [25, 26], a criticial issue is laid on controlling product selectivity. The multiple $\mathrm{CO}_{2}$ reduction reactions that produce different chemicals including $\mathrm{HCOO}^{-}, \mathrm{CO}, \mathrm{CH}_{4}, \mathrm{C}_{2} \mathrm{H}_{4}$ and $\mathrm{C}_{2} \mathrm{H}_{5} \mathrm{OH}$ can occur concurrently as described in Table 1 . In addition, HER acts as a major competing reaction. The HER is kinetically more facile than $\mathrm{CO}_{2} \mathrm{RR}$ because the number of electrons involved in the reaction is only two, and because the concentrations of proton sources such as water and bicarbonate ions are much higher than that of $\mathrm{CO}_{2}$ in the neutral or basic aqueous solutions frequently used in $\mathrm{CO}_{2} \mathrm{RR}$ experiments [27]. Due to the thermodynamic as well as kinetic reasons, selectively converting $\mathrm{CO}_{2}$ to desirable products at low overpotential is challenging. To overcome the issues, we need to deeply understand crucial factors that affect the $\mathrm{CO}_{2} \mathrm{RR}$ properties.

Previously, Hori et al. [16] have shown that the product selectivity changes with the type of transition metal

Table 1 Standard reduction potential of electrochemical $\mathrm{CO}_{2}$ reduction

\begin{tabular}{|c|c|c|}
\hline Half reaction & Number of electron & $\begin{array}{l}\text { Potential (V vs. } \\
\text { SHE) at pH } 7\end{array}$ \\
\hline $\mathrm{CO}_{2}(\mathrm{~g})+\mathrm{e}^{-} \rightarrow{ }^{*} \mathrm{COO}^{-}$ & 1 & -1.90 \\
\hline $\mathrm{CO}_{2}(\mathrm{~g})+2 \mathrm{H}^{+}+2 \mathrm{e}^{-} \rightarrow \mathrm{HCOOH}(\mathrm{l})$ & 2 & -0.61 \\
\hline $\mathrm{CO}_{2}(\mathrm{~g})+\mathrm{H}_{2} \mathrm{O}(\mathrm{l})+2 \mathrm{e}^{-} \rightarrow \mathrm{HCOO}^{-}(\mathrm{aq})+\mathrm{OH}^{-}$ & 2 & -0.43 \\
\hline $\mathrm{CO}_{2}(\mathrm{~g})+2 \mathrm{H}^{+}+2 \mathrm{e}^{-} \rightarrow \mathrm{CO}(\mathrm{g})+\mathrm{H}_{2} \mathrm{O}(\mathrm{l})$ & 2 & -0.53 \\
\hline $\mathrm{CO}_{2}(\mathrm{~g})+\mathrm{H}_{2} \mathrm{O}(\mathrm{l})+2 \mathrm{e}^{-} \rightarrow \mathrm{CO}(\mathrm{g})+2 \mathrm{OH}^{-}$ & 2 & -0.52 \\
\hline $\mathrm{CO}_{2}(\mathrm{~g})+4 \mathrm{H}^{+}+4 \mathrm{e}^{-} \rightarrow \mathrm{HCHO}(\mathrm{I})+\mathrm{H}_{2} \mathrm{O}(\mathrm{I})$ & 4 & -0.48 \\
\hline $\mathrm{CO}_{2}(\mathrm{~g})+3 \mathrm{H}_{2} \mathrm{O}(\mathrm{l})+4 \mathrm{e}^{-} \rightarrow \mathrm{HCHO}(\mathrm{g})+4 \mathrm{OH}^{-}$ & 4 & -0.89 \\
\hline $\mathrm{CO}_{2}(\mathrm{~g})+6 \mathrm{H}^{+}+6 \mathrm{e}^{-} \rightarrow \mathrm{CH}_{3} \mathrm{OH}(\mathrm{l})+\mathrm{H}_{2} \mathrm{O}(\mathrm{l})$ & 6 & -0.38 \\
\hline $\mathrm{CO}_{2}(\mathrm{~g})+5 \mathrm{H}_{2} \mathrm{O}(\mathrm{I})+6 \mathrm{e}^{-} \rightarrow \mathrm{CH}_{3} \mathrm{OH}(\mathrm{I})+6 \mathrm{OH}^{-}$ & 6 & -0.81 \\
\hline $\mathrm{CO}_{2}(\mathrm{~g})+8 \mathrm{H}^{+}+8 \mathrm{e}^{-} \rightarrow \mathrm{CH}_{4}(\mathrm{~g})+2 \mathrm{H}_{2} \mathrm{O}(\mathrm{l})$ & 8 & -0.24 \\
\hline $\mathrm{CO}_{2}(\mathrm{~g})+6 \mathrm{H}_{2} \mathrm{O}(\mathrm{I})+8 \mathrm{e}^{-} \rightarrow \mathrm{CH}_{3} \mathrm{OH}(\mathrm{I})+8 \mathrm{OH}^{-}$ & 8 & -0.25 \\
\hline $2 \mathrm{CO}_{2}(\mathrm{~g})+12 \mathrm{H}^{+}+12 \mathrm{e}^{-} \rightarrow \mathrm{C}_{2} \mathrm{H}_{4}(\mathrm{~g})+4 \mathrm{H}_{2} \mathrm{O}(\mathrm{l})$ & 12 & 0.06 \\
\hline $2 \mathrm{CO}_{2}(\mathrm{~g})+8 \mathrm{H}_{2} \mathrm{O}(\mathrm{I})+12 \mathrm{e}^{-} \rightarrow \mathrm{C}_{2} \mathrm{H}_{4}(\mathrm{~g})+12 \mathrm{OH}^{-}$ & 12 & -0.34 \\
\hline $2 \mathrm{CO}_{2}(\mathrm{~g})+12 \mathrm{H}^{+}+12 \mathrm{e}^{-} \rightarrow \mathrm{C}_{2} \mathrm{H}_{5} \mathrm{OH}(\mathrm{g})+3 \mathrm{H}_{2} \mathrm{O}(\mathrm{l})$ & 12 & 0.08 \\
\hline $2 \mathrm{CO}_{2}(\mathrm{~g})+9 \mathrm{H}_{2} \mathrm{O}(\mathrm{l})+12 \mathrm{e}^{-} \rightarrow \mathrm{C}_{2} \mathrm{H}_{5} \mathrm{OH}(\mathrm{g})+12 \mathrm{OH}^{-}$ & 12 & -0.33 \\
\hline
\end{tabular}


electrodes, from the systematic investigation on the $\mathrm{CO}_{2} \mathrm{RR}$ activity of various metal foils. They categorized transition metals into four groups on the basis of product distribution. The first group consists of metals producing $\mathrm{H}_{2}$ gas dominantly like Pt, Ir, Fe, Co and Ni metals. The second group includes the metals of which primary product is $\mathrm{CO}$ such as $\mathrm{Au}, \mathrm{Ag}$ and $\mathrm{Zn}$. Third group includes metals such as $\mathrm{Cd}$, In, Sn, etc. and their primary product is $\mathrm{HCOO}^{-}$. The last group contains only $\mathrm{Cu}$ which is a unique single metal that can produce various hydrocarbons and alcohols including $\mathrm{CH}_{4}, \mathrm{C}_{2} \mathrm{H}_{4}, \mathrm{C}_{2} \mathrm{H}_{5} \mathrm{OH}$ and $\mathrm{C}_{3} \mathrm{H}_{7} \mathrm{OH}$.

Recently, the experimental trend firstly demonstrated by Hori et al. could be understood from DFT calculation studies. The theoretical simulation results revealed that the intrinsic $\mathrm{CO}_{2} \mathrm{RR}$ selectivity on various metal surfaces is closely related with the binding energy of reaction intermediates [28-30]. Norskov group explained that $\mathrm{Au}$ and $\mathrm{Ag}$ metals, representative catalysts for $\mathrm{CO}$ production, have weak "CO binding energy, which allows for *CO desorption rather than further hydrogenation toward ${ }^{*} \mathrm{CHO}$ and ${ }^{*} \mathrm{COH}$ as shown in Fig. 1 [30]. Additionally, the $\mathrm{Au}$ and $\mathrm{Ag}$ metal can show a low catalytic activity for HER because of the weak binding energy of " $\mathrm{H}$. In contrast, the $\mathrm{Ni}, \mathrm{Pt}, \mathrm{Pd}$ and $\mathrm{Rh}$ metals which dominantly produce $\mathrm{H}_{2}$, have too strong "CO binding energy to evolve " $\mathrm{CO}$, whereas HER is facilitated due to their ideal ${ }^{*} \mathrm{H}$ binding energy based on Sabatier principle. Exceptionally, the $\mathrm{Cu}$ metal has a medium " $\mathrm{CO}$ binding energy and relatively unfavorable limiting potential for HER. Thereby, further hydrogenation of "CO intermediates can proceed at the catalyst surface, generating various hydrocarbons and alcohols.

While the binding energy of the key reaction intermediates can give us important insights as a descriptor to understand intrinsic activity of various metals, enhancing their catalytic properties such as selectivity and overpotential is limited by scaling relations between the binding energies of various intermediates. For instance, the binding energies for ${ }^{*} \mathrm{COOH}$ and ${ }^{*} \mathrm{CO}$ intermediates are correlated on transition metals by the equation, $\Delta \mathrm{G}_{\mathrm{CO}}=1.31 \times \Delta \mathrm{G}_{\mathrm{COOH}}-0.47$ [5]. Thus, the binding energies are hard to be controlled independently although stronger binding of " $\mathrm{COOH}$ and weaker binding of " $\mathrm{CO}$ is required to efficiently promote $\mathrm{CO}$ production. In addition, the scaling relation also exists between

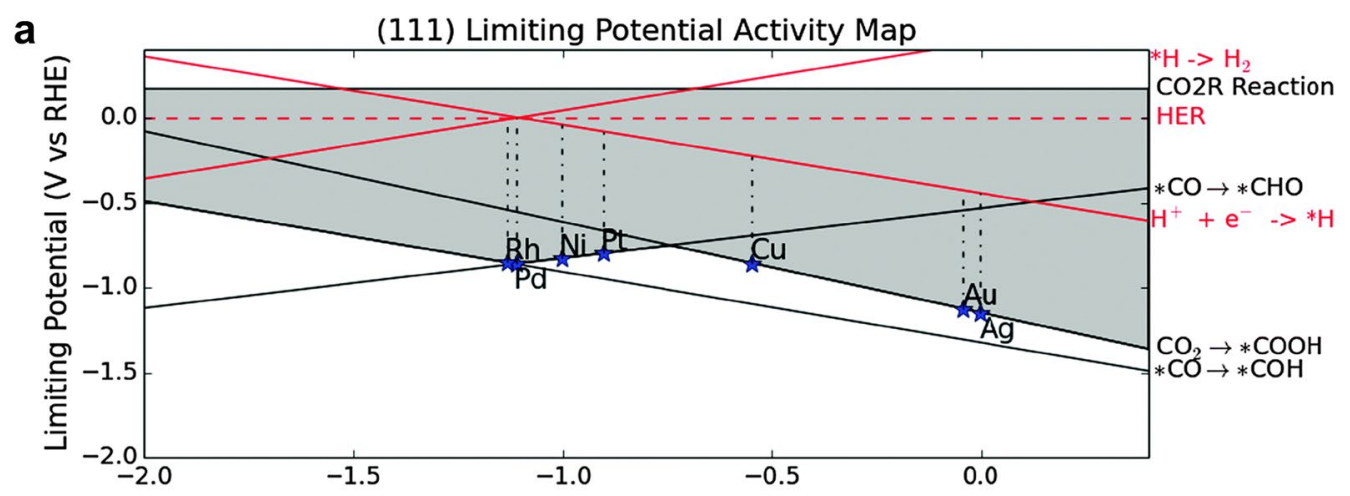

b

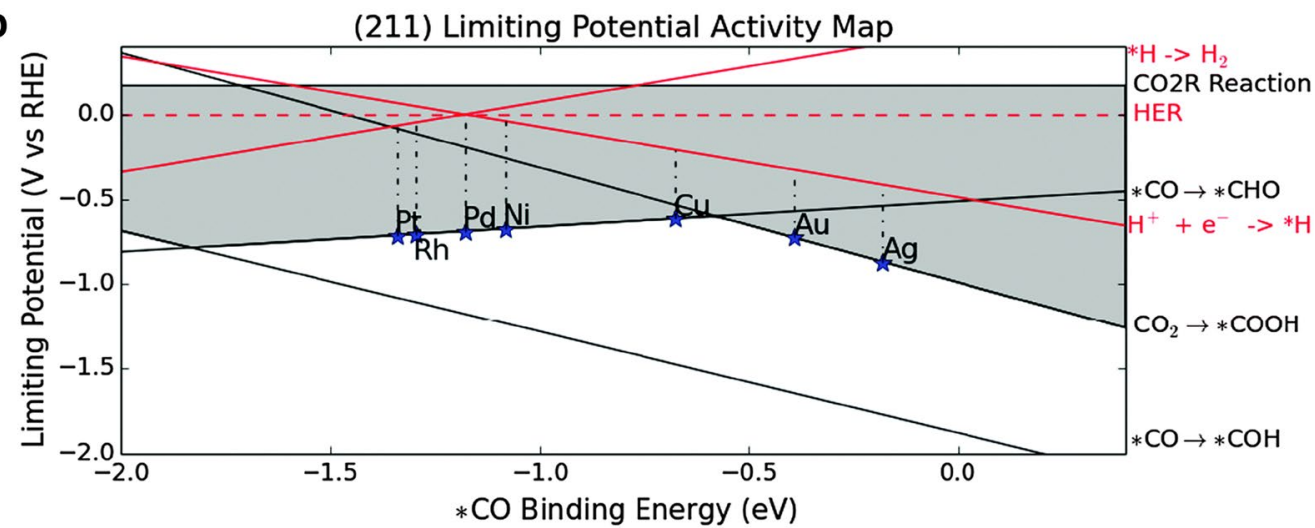

Fig. 1 Limiting potential activity map of $\mathrm{CO}_{2}$ reduction on the $\mathbf{a}(111)$ and $\mathbf{b}$ (211) surface of FCC transition metals (Reproduced with permission from [30], copyright 2014 Royal Society of Chemistry) 
the intermediate binding energies of ${ }^{*} \mathrm{COOH}$ and ${ }^{*} \mathrm{H}$ based on the equation, $\Delta \mathrm{G}_{\mathrm{COOH}}=1.65 \times \Delta \mathrm{G}_{\mathrm{H}}+0.02$ [5]. which also makes it difficult to selectively suppress HER. In this regard, breaking these scaling relations is critical in enhancing the catalyst properties for $\mathrm{CO}_{2} \mathrm{RR}$. In the following chapter, we outline recent strategies that allow for the independent modulation of the binding energy for specific intermediate, in terms of catalyst development and eletrolyte engineering.

\section{Strategies to tune intermediate binding}

\subsection{Oxygen incorporation}

Electrochemically reduced copper oxides, i.e. oxidederived $\mathrm{Cu}(\mathrm{OD}-\mathrm{Cu})$, have been intensively studied as an electrocatalyst for the production of $\mathrm{C}_{2+}$ chemicals from $\mathrm{CO}_{2} \mathrm{RR}[20,24,31$ ], since $\mathrm{Li}$ et al. [32] first reported that the OD-Cu electrode can promote $\mathrm{C}-\mathrm{C}$ coupling reactions with the suppression of HER in $\mathrm{CO}$ reduction reactions (CORR). It is known that the $\mathrm{C}-\mathrm{C}$ coupling reactions in $\mathrm{CO}_{2} \mathrm{RR}$ actually proceed via similar pathways with those of CORR, such as CO dimerization [33, 34], therefore the OD-Cu electrode can show the enhanced $\mathrm{C}-\mathrm{C}$ coupling capability even in $\mathrm{CO}_{2} \mathrm{RR}$. The promotional effect of the OD-Cu electrode has been explained based on several hypotheses. Feng et al. [35] demonstrated that surface density of grain boundary is correlated with the catalytic activity of $\mathrm{CO}$ reduction, suggesting that defective grain boundary formed by oxidation treatment is an active site for $\mathrm{C}-\mathrm{C}$ coupling reactions. Meanwhile, Xiao et al. [36] showed from DFT calculations that the $\mathrm{Cu}_{2} \mathrm{O}-\mathrm{Cu}$ interface can lower the energetic barrier of $\mathrm{C}-\mathrm{C}$ bond formation by attractive electrostatics between two carbon atoms bound to $\mathrm{Cu}^{+}$ and $\mathrm{Cu}^{0}$ atoms, respectively. Furthermore, it has been proposed that subsurface oxygen $\left(\mathrm{O}_{\text {sub }}\right)$ plays an important role in modulating the binding strength of $\mathrm{CO}$ molecules which are known to be a key intermediate for $\mathrm{C}-\mathrm{C}$ coupling reaction [20]. Here, we explain the promotional effect of OD-Cu electrodes focusing on the subsurface oxygen.

Eilert et al. [20] performed in situ ambient pressure $\mathrm{X}$-ray photoelectron spectroscopy (APXPS) analysis to identify that oxygen species can be stably maintained at the surface even after applying cathodic potentials enough to reduce $\mathrm{Cu}$ oxides. Figure 2a shows the $\mathrm{O} 1 \mathrm{~s}$ APXPS spectra of the initial, oxidized, and reduced $\mathrm{Cu}$ foil. After oxidation, much thicker water overlayer was formed and oxidized compounds assignable to $\mathrm{CuCO}_{3}$, $\mathrm{Cu}(\mathrm{OH})_{2}$ and $\mathrm{Cu}_{2} \mathrm{O}$ were created. After re-reduction, they found that an oxygen peak increased much more in comparison with the initial spectrum of $\mathrm{Cu}$ foil. They hypothesized that the enhanced oxygen peak can be attributed to the formation of $\mathrm{O}_{\text {sub }}$, based on the peak position and additional oxygen K-edge electron energyloss spectra (EELS) analysis.

In order to elucidate the influence of $\mathrm{O}_{\text {sub }}$ in $\mathrm{CO}_{2} \mathrm{RR}$ properties, the $\mathrm{CO}$ binding energy was calculated on clean $\mathrm{Cu}(100)$ and on $\mathrm{Cu}(100)$ with subsurface
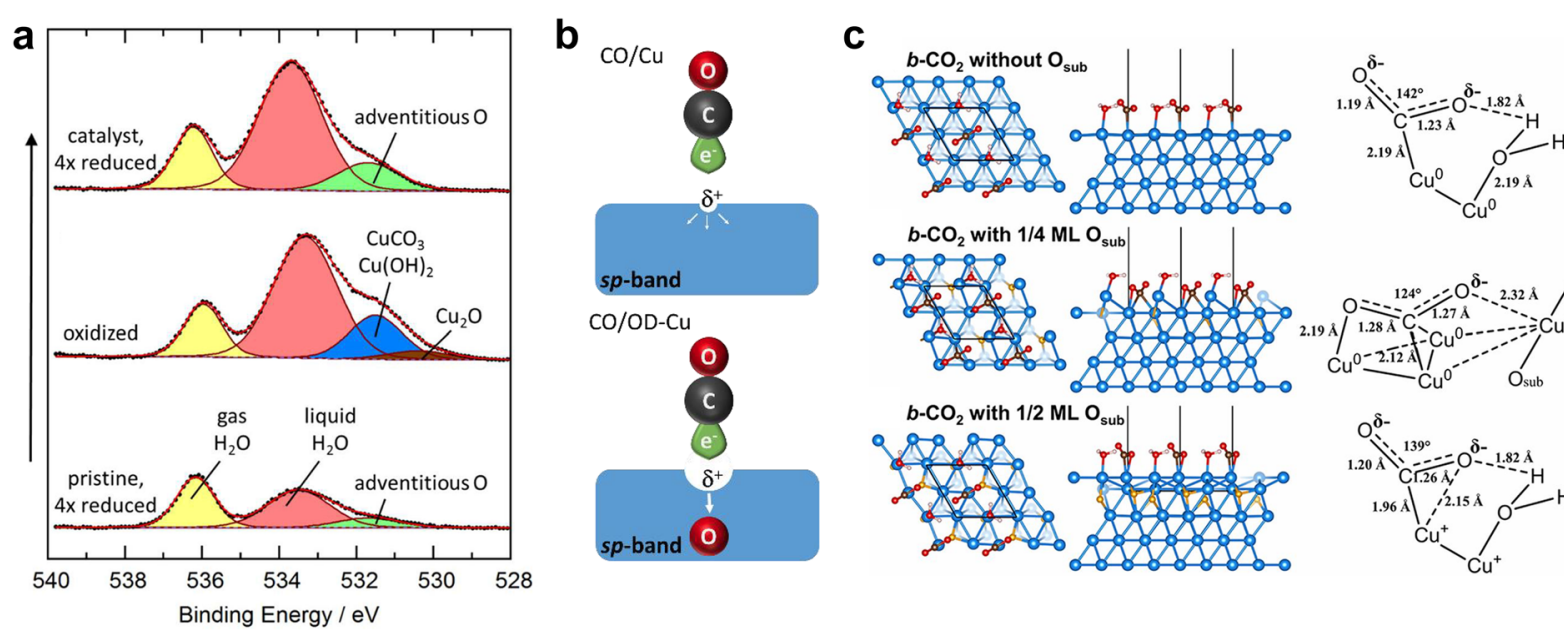

Fig. 2 The direct observation of subsurface oxygens $\left(\mathrm{O}_{\text {sub }}\right)$ and their effects on intermediate binding. a In situ O 1 s APXPS spectra of Cu foil depending on electrochemical reduction/oxidation treatments. Oxidation of the reduced Cu foil leads to the formation of a thick water overlayer and oxidized compounds such as $\mathrm{CuCO}_{3}, \mathrm{Cu}(\mathrm{OH})_{2}$, and $\mathrm{Cu}_{2} \mathrm{O}$. Initially oxidized and then reduced $\mathrm{Cu}$ foil contains more adventitious oxygen (green). b Illustration of $\mathrm{CO}$ binding on $\mathrm{Cu}$ and oxide-derived $\mathrm{Cu}\left(\mathrm{OD}-\mathrm{Cu}\right.$ ) with $\mathrm{O}_{\text {sub. }} \mathbf{c}$ Predicted structures of bent $\mathrm{CO}_{2}\left(b-\mathrm{CO}_{2}\right)$ and $\mathrm{H}_{2} \mathrm{O}$ molecules on $\mathrm{Cu}(111)$ with different levels of $\mathrm{O}_{\text {sub }}$. Free energies for $\mathrm{CO}_{2}$ activation to $b-\mathrm{CO}_{2}$ are calculated to be $+1.07,-0.06,+0.28 \mathrm{eV}$ on pristine $\mathrm{Cu}(111)$, $\mathrm{Cu}(111)$ with $1 / 4 \mathrm{ML} \mathrm{O}_{\text {sub, }}$ and $\mathrm{Cu}(111)$ with $1 / 2 \mathrm{ML} \mathrm{O}_{\text {sub }} \mathbf{a}-\mathbf{b}$ (Reproduced with permission from [20], copyright 2017 American Chemical Society. $\mathbf{c}$ Reproduced with permission from [37], copyright 2017 National Academy of Sciences) 
oxygens in different layers below surface. The $\mathrm{CO}$ binding became stronger in the presence of subsurface oxygens. Such enhancement of $\mathrm{CO}$ binding was explained by local charge interaction between $\mathrm{O}_{\text {sub }}$ and a $\mathrm{Cu}$ atom as shown in Fig. 2b. The $\mathrm{O}_{\text {sub }}$ could withdraw electrons from $\mathrm{Cu}$ sp-band, and lower the $\sigma$-repulsion between a $\mathrm{Cu}$ atom and $\mathrm{CO}$ molecule. Ultimately, it was suggested that stronger $\mathrm{CO}$ binding leads to a higher $\mathrm{CO}$ coverage at the catalyst surface, and kinetically promotes $\mathrm{C}-\mathrm{C}$ coupling reactions over hydrogenation reactions such as $\mathrm{CH}_{4}$ and $\mathrm{H}_{2}$ evolutions.

It is also reported that the $\mathrm{O}_{\text {sub }}$ can lower the activation barrier for the transition from a physisorbed linear $\mathrm{CO}_{2}\left(l-\mathrm{CO}_{2}\right)$ to a bent chemisorbed $\mathrm{CO}_{2}\left(b-\mathrm{CO}_{2}\right)$. Favaro et al. [37] predicted the binding structures of chemisorbed $\mathrm{CO}_{2}$ and $\mathrm{H}_{2} \mathrm{O}$ on $\mathrm{Cu}$ (111) with different levels of $\mathrm{O}_{\text {sub }}$ (Fig. 2c). Also, they identified that the free energies of the chemisorbed systems depend on $\mathrm{O}_{\text {sub }}$ levels. When 0.25 mono-layer (ML) $\mathrm{O}_{\text {sub }}$ was incorporated, the free energy was much lowered in comparison with unmodified $\mathrm{Cu}$ (111). The presence of $\mathrm{O}_{\text {sub }}$ generated a heterovalent surface composed of $\mathrm{Cu}^{0}$ and $\mathrm{Cu}^{+}$atoms, where the $\mathrm{Cu}^{0}$ and $\mathrm{Cu}^{+}$centers were synergistically bound to the $\mathrm{C}$ and $\mathrm{O}$ atoms of the $b-\mathrm{CO}_{2}$, respectively. The electronic interactions between the binding centers and the adsorbed species stabilized $b$ $\mathrm{CO}_{2}$ structure significantly.

However, there are still on-going discussions as to whether the lattice oxygen is stable under highly cathodic conditions. Mandal et al. synthesized $\mathrm{Cu}_{2} \mathrm{O}$ catalysts and investigated their reduction behavior using in situ Raman spectroscopy [38]. They found that $\mathrm{Cu}_{2} \mathrm{O}$ signals completely disappeared during initial $3 \mathrm{~min}$ at $\mathrm{CO}_{2} \mathrm{RR}$ conditions, and $\mathrm{CO}_{2}$ reduction products were detected after complete reduction by selected-ion flow tube mass spectrometry (SIFT-MS). The experimental result was also supported by DFT calculation that $\mathrm{Cu}_{2} \mathrm{O}$ reduction is energetically preferred over $\mathrm{CO}_{2}$ RR. Moreover, Lum et al. [39] also identified from ${ }^{18} \mathrm{O}$ labelling experiments where the oxygen species of OD-Cu catalysts were observed to survive less than $1 \%$ of the original oxygen content. In contrast, it has been proposed that the $\mathrm{O}_{\text {sub }}$ can be stably sustained in (100) surfaces of $\mathrm{Cu}$ nanocubes and amorphous surface layers due to their disordered nature $[40,41]$, although $\mathrm{O}_{\text {sub }}$ is not stable in ordered $\mathrm{Cu}$ slab models. In fact, it has been reported that loss of $\mathrm{Cu}$ cube morphology by roughening during $\mathrm{CO}_{2} \mathrm{RR}$ caused the absence of $\mathrm{Cu}^{+}$signals and the increase in HER over $\mathrm{CO}_{2} \mathrm{RR}$ [42]. The aggregated amorphous nanoclusters of $\mathrm{Cu}_{2}(\mathrm{OH})_{3} \mathrm{Cl}$ were also found to have the mixed metal valency of $\mathrm{Cu}^{+}$and $\mathrm{Cu}^{0}$ at highly cathodic potentials [33].

\subsection{Electrolyte engineering}

The cations and anions contained in an aqueous electrolyte also play an important role in controlling the product selectivity. Resasco et al. [23] measured the partial current densities of $\mathrm{CO}_{2} \mathrm{RR}$ on $\mathrm{Cu}(111)$ using different alkali metal cations such as $\mathrm{Li}^{+}, \mathrm{Na}^{+}, \mathrm{K}^{+}, \mathrm{Rb}^{+}$and $\mathrm{Cs}^{+}$as shown in Fig. 3a. Interestingly, as the cation size became larger, the partial current densities for $\mathrm{HCOO}^{-}, \mathrm{C}_{2} \mathrm{H}_{4}$ and $\mathrm{C}_{2} \mathrm{H}_{5} \mathrm{OH}$ production increased while the production rates of $\mathrm{H}_{2}, \mathrm{CO}$ and $\mathrm{CH}_{4}$ were unchanged. Larger cation size facilitated the $\mathrm{CO}_{2}$ activation over HER as well as the $\mathrm{C}_{2}$ production over $\mathrm{C}_{1}$. The effect of cation on product distribution was explained by electrostatic interactions between the intermediates and the solvated cations at the outer Helmholtz plane. Based on DFT calculation, it was demonstrated that larger cations are more stabilized in the outer Helmholtz plane at the $\mathrm{Cu}$ (111) surface (Fig. 3b), and show higher coverage near the catalyst surface. The stabilized cations facilitated the adsorption of intermediates with large dipole moments (e.g., " $\mathrm{CO}_{2}$, "CO, $\left.{ }^{*} \mathrm{OCCO}\right)$ over $" \mathrm{H}$ intermediate with a negligible dipole moment through an electric field (Fig. 3c).

It has been also suggested that the other role of hydrated cations is to control the local $\mathrm{CO}_{2}$ concentration near the catalyst surface. Singh et al. [43] reported that cation hydrolysis occurs near the cathode surface during $\mathrm{CO}_{2}$ reduction. As the cation migrates toward the negatively polarized electrode, an increasing electrostatic interaction can reduce the $\mathrm{p} K_{\mathrm{a}}$ for hydrolysis. If the local $\mathrm{pH}$ is higher than the $\mathrm{p} K_{\mathrm{a}}$ of the hydrated cations, the dissociation of a water in the hydration shell releases protons, and buffers the change of local $\mathrm{pH}$. The buffering ability declines in the order of $\mathrm{Cs}^{+}>\mathrm{Rb}^{+}>\mathrm{K}^{+}>\mathrm{Na}^{+}>\mathrm{Li}^{+}$. As local $\mathrm{CO}_{2}$ concentration competes with local $\mathrm{pH}$ due to the equilibrium reactions between $\mathrm{CO}_{2}, \mathrm{HCO}_{3}{ }^{-}$and $\mathrm{CO}_{3}{ }^{2-}$ species, the $\mathrm{pH}$ decreases and the $\mathrm{CO}_{2}$ concentration increases near the cathode with increasing cation size.

Furthermore, Dinh et al. [44] found that higher concentration of $\mathrm{OH}^{-}$ions can facilitate $\mathrm{CO}_{2}$ activation on the $\mathrm{Cu}$-coated gas diffusion layer (GDL) electrodes. When linear sweep voltammetry (LSV) curves under $\mathrm{CO}_{2}$ and Ar flow were scanned in the electrolytes of various $\mathrm{KOH}$ concentrations, the onset of LSV curves recorded under $\mathrm{CO}_{2}$ shifted markedly to more positive potentials with increasing $\mathrm{KOH}$ concentration, whereas the onset under Ar remained similar. Furthermore, at $10 \mathrm{M} \mathrm{KOH}$ concentration, the onset potentials for $\mathrm{CO}$ and $\mathrm{C}_{2} \mathrm{H}_{4}$ production were similar, whereas the onset potential gap between $\mathrm{CO}$ and $\mathrm{C}_{2} \mathrm{H}_{4}$ is observed at low $\mathrm{KOH}$ concentration because the build-up of $\mathrm{CO}$ coverage is required to proceed $\mathrm{CO}$ dimerization. Therefore, high $\mathrm{KOH}$ concentration made $\mathrm{CO}$ dimerization much 

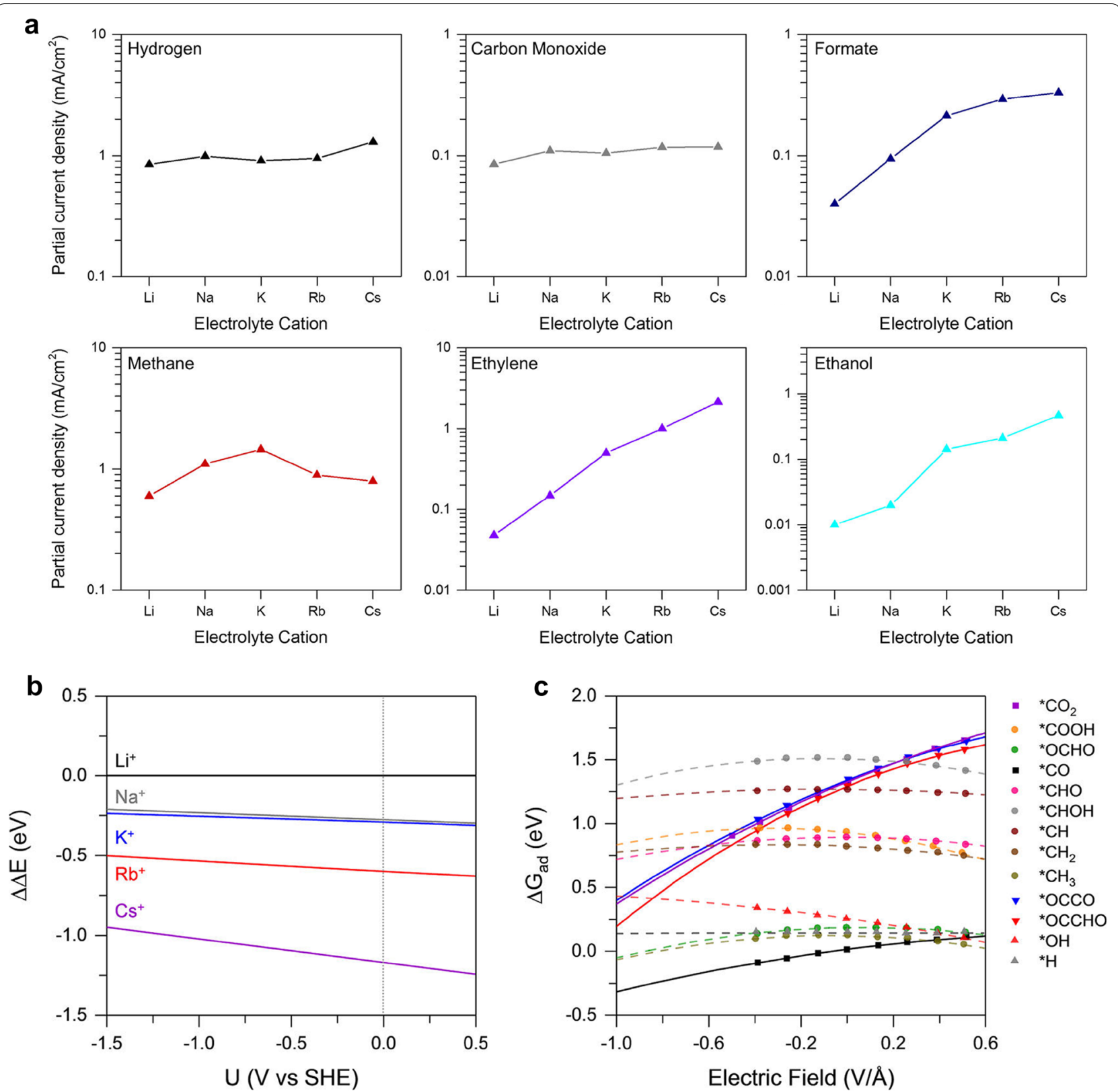

Fig. 3 Cation effects on the stabilization of reaction intermediates. a Partial current densities for $\mathrm{H}_{2}, \mathrm{CO}_{1} \mathrm{HCOO}^{-}, \mathrm{CH}_{4}, \mathrm{C}_{2} \mathrm{H}_{4}$ and $\mathrm{C}_{2} \mathrm{H}_{5} \mathrm{OH}$ production on $\mathrm{Cu}(111)$ as a function of alkali metal cations included in an electrolyte. $\mathbf{b}$ The energy change occuring from the transport of a solvated cation from bulk electrolyte to the outer Helmholtz plane at the $\mathrm{Cu}$ (111) surface as a function of potential and cation type. c The effect of electric field on the adsorption free energies of various $\mathrm{CO}_{2} \mathrm{RR}$ intermediates on $\mathrm{Cu}$ (111) (a-c Reproduced with permission from [23], copyright 2017 American Chemical Society)

easier. Based on DFT calculation, they proposed that the hydroxide adsorption increases the charge imbalance between carbon atoms in the *OCCO intermediate. As a result, the dipole interaction between the carbon atoms more stabilized the "OCCO, and reduced the activation barrier for $\mathrm{CO}$ dimerization step.

\subsection{Nanostructuring}

Sharpening metal can perturb the local electron density of metal surface and enhance the local electric field because free electrons migrate to sharp regions due to electrostatic repulsion. The field enhancement effect by tip electrode can be exploited for improving the $\mathrm{CO}_{2} \mathrm{RR}$ 
properties. Liu et al. [22] simulated the electron density distribution on various electrode surfaces as a function of tip radius (Fig. 4a). It was shown that the tip-concentrated electron density dramatically increases as the electrodes sharpen. The tip sharpening from a radius of 140 to $5 \mathrm{~nm}$ enhanced electrostatic field intensity from approximately 3 to $43 \mathrm{MV} \mathrm{m}^{-1}$. The enhancement of electric field also affected the concentration of surrounding alkali metal cations. The adsorbed $\mathrm{K}^{+}$density at the tip elevated 20 -fold due to the field enhancement (Fig. 4b). The highly concentrated cations can help to tune the free energy of adsorption of intermediates of $\mathrm{CO}_{2} \mathrm{RR}$ through the electrostatic interaction. According to DFT calculation study, the $\mathrm{K}^{+}$ions greatly lowered free energy of " $\mathrm{COOH}$ and " $\mathrm{CO}$ adsorption, in comparison with the case without $\mathrm{K}^{+}$ions (Fig. 4c). Based on these theoretical results, they attempted to measure the electrochemical $\mathrm{CO}_{2}$ reduction properties of $\mathrm{Au}$ needles, rods and particles. Surprisingly, Au needle electrodes exhibited a dramatic enhancement in $\mathrm{CO}_{2} \mathrm{RR}$ selectivity, as well as the onset potential shift to lower overpotentials (Fig. 4d). From Kelvin probe atomic force microscopy and inductively coupled plasma optical emission spectrometry (ICP-OES), it was also confirmed that electric fields and adsorbed $\mathrm{K}^{+}$concentration are the highest for the needles.

Controlling the shape of catalysts has been reported to be effective even in $\mathrm{C}_{2+}$ production. Jiang et al. [45] prepared a $\mathrm{Cu}$ nanocube catalyst with exposed (100) facets through $\mathrm{Cu}^{2+}$ ion cycling method on $\mathrm{Cu}$ foil. When the cycle number increased from 0 to 100 cycles, the $\mathrm{FE}$ of $\mathrm{C}_{2+}$ products was dramatically enhanced from 26.0 to $60.6 \%$. Concurrently, the $\mathrm{FE}$ of $\mathrm{C}_{1}$ products decreased from 59.1 to $22.7 \%$. The enhanced $\mathrm{C}-\mathrm{C}$ coupling capability was attributed to the exposure of (100) facets in addition to local $\mathrm{pH}$ effect resulting from high surface area because activity enhancement in the $\mathrm{C}_{2+}$ production was observed in low overpotential regions where mass transport effects can be neglected. According to DFT calculation, the $\mathrm{Cu}(100)$ surface showed stronger $\mathrm{CO}$ binding as well as lower $\mathrm{CO}$ dimerization barrier compared to $\mathrm{Cu}$ (111) surface. As a result, higher selectivity toward $\mathrm{C}_{2+}$ products was achieved. In addition to the facet-controlling strategy, constructing nanocavities at the catalyst surface can promote $\mathrm{C}_{2}-\mathrm{C}_{1}$ coupling to form $\mathrm{C}_{3}$ products. Zhuang et al. [34] simulated the spatial concentrations and flux distribution of $\mathrm{CO}, \mathrm{C}_{2}$ and $\mathrm{C}_{3}$ species using a hollow spherical shell with a circular a
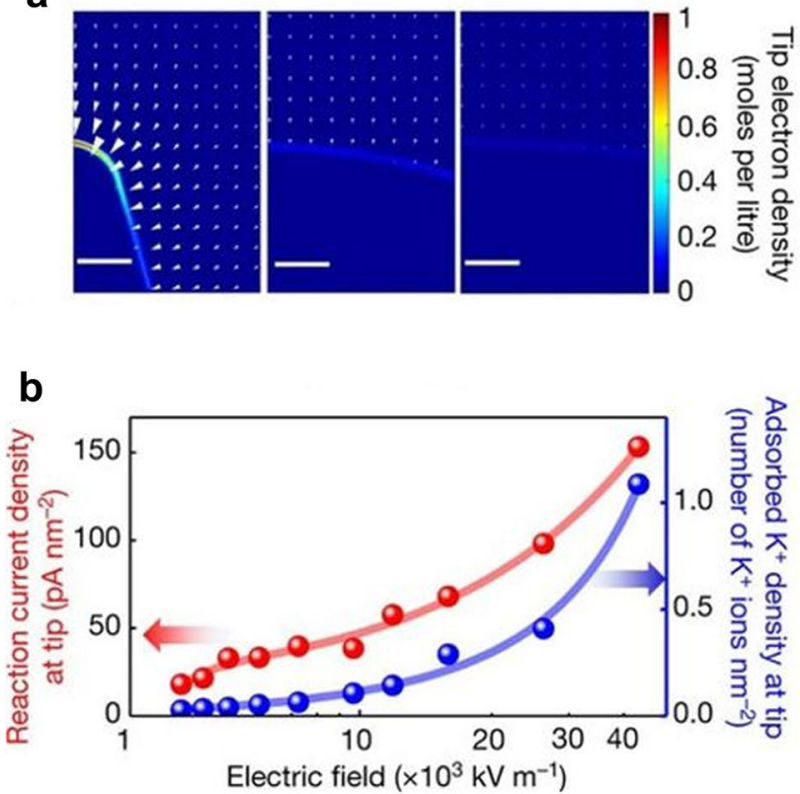
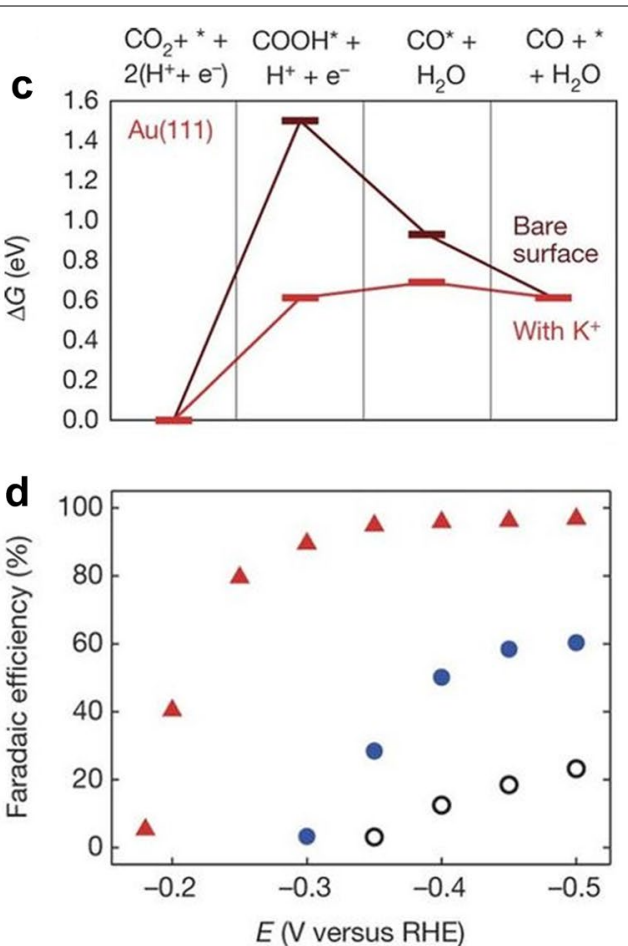

Fig. 4 Electric field enhancement and the impacts on $\mathrm{CO}_{2}$ reduction properties on nanoneedle catalysts. a Free electron density distribution on the Au electrodes with different tip radius. The tip radius of the structure is 5, 60 and $140 \mathrm{~nm}$ for left, middle and right panels. b Adsorbed $\mathrm{K}^{+}$density and current density distributions on the surface of Au needles. c Free energy diagrams of the electrochemical CO production on Au (111) surface in the presence of adsorbed $\mathrm{K}^{+}$and in the absence of adsorbed $\mathrm{K}^{+}$. $\mathbf{d}$ CO FE on Au needles, rods and particles at different applied potentials (a-d Reproduced with permission from [22], copyright 2016 Nature publishing) 
opening. They found that the inner cavity confines the mass transport of produced $\mathrm{C}_{2}$ species into exterior electrolyte, which results in higher local concentration of $\mathrm{C}_{2}$ species inside the cavity. Ultimately, the cavity structure increased surface coverage of $\mathrm{C}_{2}$ intermediate, and elevated the production rate of $\mathrm{C}_{3}$ species. To experimentally demonstrate the cavity effect, $\mathrm{Cu}$ catalysts with the cavity structure were prepared through acidic etching of $\mathrm{Cu}_{2} \mathrm{O}$ nanoparticles and then electrochemical reduction. The nanocavity $\mathrm{Cu}$ catalyst exhibited the enhanced $\mathrm{FE}$ of $21.0 \%$ towards propanol production compared to closed $\mathrm{Cu}$ nanoparticles (NPs), which was in accordance with the simulation results.

\subsection{Surface ligand effects}

The ligand assembly can induce charge rearrangement, causing the difference in the intermediate stabilization and the adsorption configuration [46-48]. Kim et al. [46] synthesized Ag NP supported by carbon black in the presence of cysteamine as a ligand, and evaluated the electrocatalytic performance. The cysteamineanchored Ag NPs showed a higher maximum FE of 84.4\% toward CO production in comparison with $70.5 \% \mathrm{FE}$ of Ag foil. More importantly, the overpotential required to achieve the $\mathrm{CO}$ partial current density of $1 \mathrm{~mA} \mathrm{~cm}{ }^{-2}$ was reduced as $300 \mathrm{mV}$ by the ligand assembly (Fig. $5 \mathrm{a}$ ). By DFT calculation study, it was found that the binding energy of " $\mathrm{COOH}$ intermediate monotonically increases as the cysteamine coverage increases, while the $\mathrm{CO}$ binding energy exhibited marginal changes from the ligand assembly (Fig. 5b). Specifically, the binding energy of " $\mathrm{COOH}$ was enhanced up to $0.26 \mathrm{eV}$ as the cysteamine/Ag ratio increases from 0 to $2.7 \%$. The preferential stabilization of * $\mathrm{COOH}$ over * $\mathrm{CO}$ led to the reduction of overpotential. Deeper mechanistic insight was taken from the spatial electron spin density analysis. When cysteamine molecules were attached, spatial localization of the unpaired electron was stabilized particularly at the Ag surface, whereas the unpaired electrons were delocalized over the entire $\mathrm{Ag}$ atoms without the cysteamine. The unpaired electrons made the $\mathrm{Ag}-\mathrm{COOH}$ bond more covalent, and stabilized the " $\mathrm{COOH}$ as a radical form.

The ligand effect has been also demonstrated with the different type of ligand for Au NP. Cao et al. [48] successfully prepared the porphyrin ligand-capped and naked $\mathrm{Au}$ NPs (denoted as P1-AuNP and naked-AuNP, respectively). The P1-AuNP showed higher electrocatalytic activity toward $\mathrm{CO}$ production compared to the nakedAuNP. At $-0.45 \mathrm{~V}$ vs. RHE, the CO FE was measured to be $93 \%$ and $44 \%$ for P1-AuNP and naked-AuNP, respectively. Moreover, at $-0.45 \mathrm{~V}$ vs. RHE, the partial current density for $\mathrm{CO}$ production was approximately sixfold higher on P1-AuNP than on naked-AuNP. Regarding the effect of porphyrin ligand, DFT calculation study showed that the formation of ${ }^{*} \mathrm{COOH}$ and ${ }^{*} \mathrm{CO}$ intermediates is more favorable as 0.55 and $0.08 \mathrm{eV}$ on $\mathrm{P} 1-\mathrm{Au}(111)$ surfaces than on $\mathrm{Au}(111)$ surfaces. The porphyrin ligand dramatically lowered the energetic barrier for " $\mathrm{COOH}$ formation step.

\subsection{Single-atom catalyst}

Recently, single-atom catalysts have attracted great attention in the research field of electrochemical $\mathrm{CO}_{2}$ reduction due to their totally different activity compared to conventional bulk metals $[49,50]$. One of the representative single-atom catalysts is metal-incorporated $\mathrm{N}$-doped
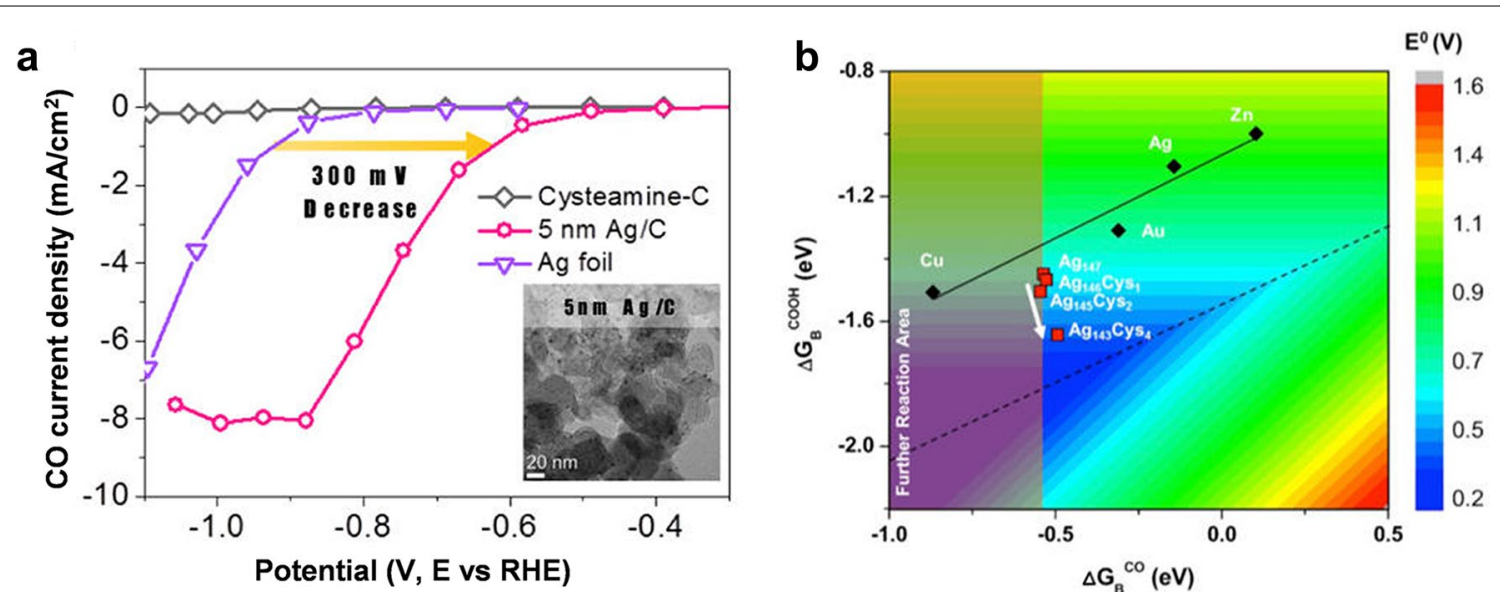

Fig. 5 The effects of introducing ligand on the metal surfaces. a CO partial current density of cysteamine-anchored Ag/C, Ag foil, and cysteamine-C samples. $\mathbf{b}$ The binding energies of the $\mathrm{COOH}$ and $\mathrm{CO}$ intermediates examined from $\operatorname{Ag}_{(147-n)} \mathrm{Cys}_{n}(n=0,1,2,4)$ models. Colored map represents the theoretical $\mathrm{CO}_{2}$ reduction potential $\left(E^{0}\right)$ as a function of $\mathrm{COOH}$ and $\mathrm{CO}$ binding free energies $\left(\triangle \mathrm{G}_{B}^{\mathrm{COOH}}\right.$ and $\left.\triangle \mathrm{G}_{B}^{\mathrm{CO}}\right)(\mathbf{a}-\mathbf{b}$ Reproduced with permission from [46], copyright 2015 American Chemical Society) 
carbon $(\mathrm{M}-\mathrm{N}-\mathrm{C})$ where a metal atom is coordinated by neighboring nitrogen atoms. Ju et al. [51] investigated the catalytic activity of $\mathrm{M}-\mathrm{N}-\mathrm{C}$ including various metals such as $\mathrm{Mn}, \mathrm{Co}, \mathrm{Fe}, \mathrm{Ni}$ and $\mathrm{Cu}$. They identified that the selectivity for $\mathrm{CO}$ production exhibit a strong dependence on the nature of metal center (Fig. 6a, b). The Co$\mathrm{N}_{\mathrm{x}}$ sites selectively produced $\mathrm{H}_{2}$ with the $\mathrm{FE}$ of $90 \%$ while the $\mathrm{Ni}-\mathrm{N}_{\mathrm{x}}$ sites showed the highest selectivity of $85 \%$ for $\mathrm{CO}$ production. To understand the experimental trend, DFT calculation study was conducted (Fig. 6c). It was discovered that $\mathrm{Co}-\mathrm{N}_{\mathrm{x}}$ sites have energetic downhill for $\mathrm{H}_{2}$ production, but represent too strong "CO adsorption to desorb the *CO. In contrast, on the $\mathrm{Ni}-\mathrm{N}_{\mathrm{x}}$ sites, the ${ }^{*} \mathrm{H}$ adsorption was energetically uphill reaction. Moreover, the formation and desorption process of the "CO intermediate had all-downhill energetics. In terms of the $\mathrm{CO}$ production rate, the $\mathrm{Ni}-\mathrm{NC}$ catalyst outperformed the state-of-the-art $\mathrm{Au}$ catalysts. The $\mathrm{CO}_{2} \mathrm{RR}$ property of the $\mathrm{Ni}-\mathrm{NC}$ catalyst is interesting, given that bulk $\mathrm{Ni}$ foil is specific for $\mathrm{H}_{2}$ production.

The special catalytic performance of single-atom metal catalysts can be attributed to the unique electronic structure of the metal center affected by surrounding coordination atoms. According to a previous study [52], it was explained that the unstable $\mathrm{Ni}(\mathrm{I})$ atoms with an unpaired electron can be stabilized by pyridinic $\mathrm{N}$ with low electronegativity in an $\mathrm{N}$-doped carbon matrix. The $\mathrm{Ni}(\mathrm{I})$ site can transfer charges spontaneously to the carbon $2 \mathrm{p}$ orbital in $\mathrm{CO}_{2}$, forming a $\mathrm{CO}_{2}^{\delta-}$ species (Fig. 6d). Such an electronic interaction helps to reduce the energy barrier for electrochemical $\mathrm{CO}_{2}$ reduction. However, it should be also considered that various $\mathrm{N}$ species present in the $\mathrm{N}$-doped carbons can act as an active site, in addition to $\mathrm{M}-\mathrm{N}_{\mathrm{x}}$ sites. Jung et al. investigated the catalytic

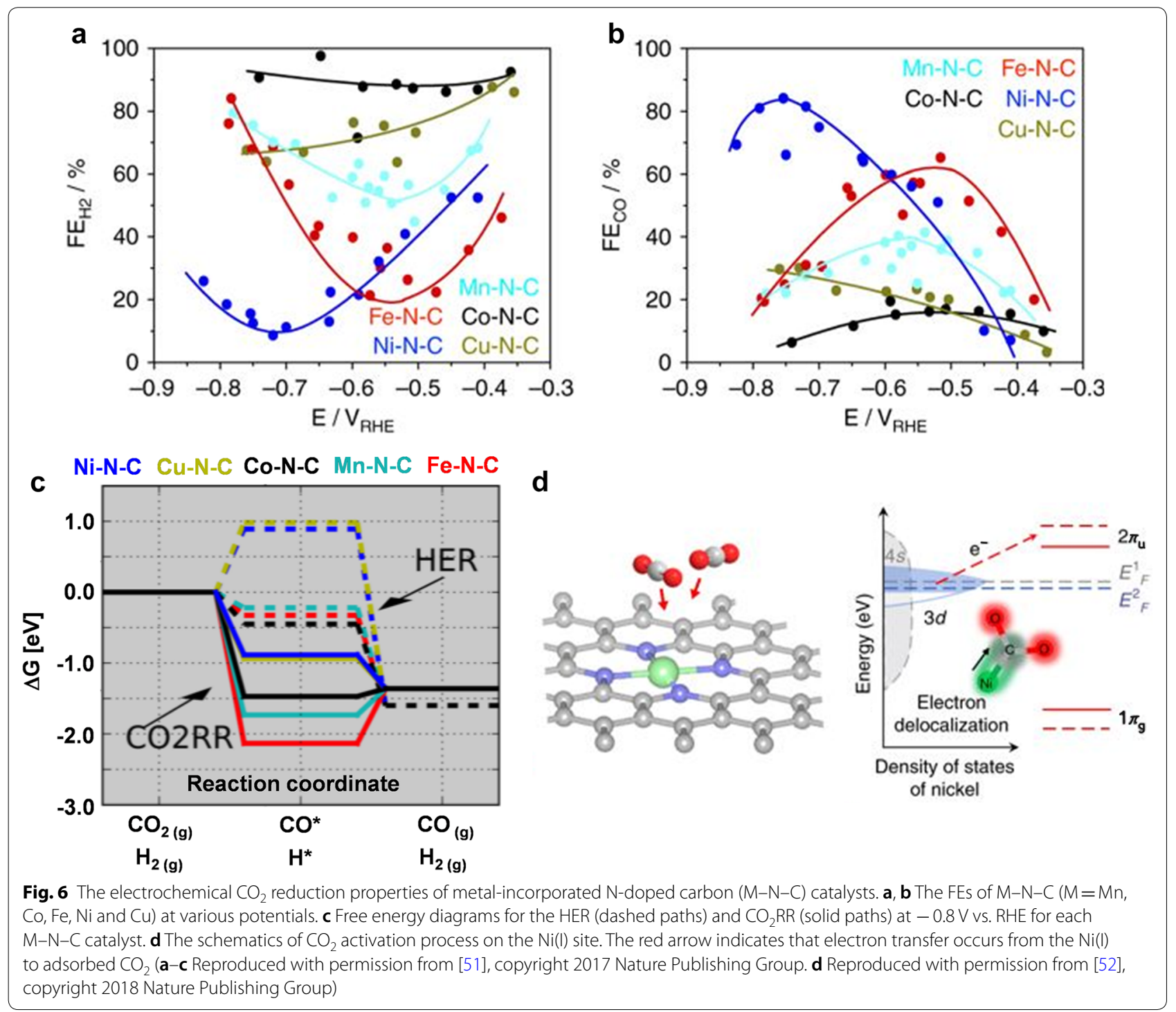


performance of various $\mathrm{M}-\mathrm{N}-\mathrm{C}(\mathrm{M}=\mathrm{Fe}, \mathrm{Co}, \mathrm{Cu})$ catalysts for $\mathrm{CO}_{2} \mathrm{RR}$ [53]. The maximum $\mathrm{FE}$ for $\mathrm{CO}$ production increased in the order of $\mathrm{Cu}-\mathrm{NC}<\mathrm{Co}-\mathrm{NC}<\mathrm{Fe}-\mathrm{NC}$. The maximum FE values were considered to be related with the atomic contents of pyridinic, pyrrolic, and graphitic N species based on XPS analysis. The catalysts containing higher pyridinic and graphitic $\mathrm{N}$ contents with lower pyrrolic $\mathrm{N}$ contents showed a higher selectivity toward CO production. Previous DFT calculation study also proposed that the $\mathrm{N}$ species in $\mathrm{N}$-doped carbon nanotubes (NCNTs) can lower the energy barrier for * $\mathrm{COOH}$ formation because the $\mathrm{N}$ defects have lonepair electrons and can donate electrons to the intermediate with strong binding, although the promotional effect depends on the type of $\mathrm{N}$ species [54].

\section{Conclusions}

In summary, we have reviewed recent strategies for enhancing electrocatalytic properties of $\mathrm{CO}_{2}$ reduction reactions, and discussed new insights in terms of intermediate binding energy based on the DFT calculation results. Theoretically, suppressing the $\mathrm{H}_{2}$ evolution and improving the selectivity for a specific product on pure metal surfaces are limited by scaling relations between the binding energies of reaction intermediates, whereas it has been demonstrated that the binding energies can be tuned independently by implementing electronic perturbation and electrostatic interaction. Specifically, incoporating oxygens into the $\mathrm{Cu}$ surface stabilized the bent chemisorbed $\mathrm{CO}_{2}$ and strenghthened the $\mathrm{CO}$ binding, which kinetically promoted $\mathrm{C}-\mathrm{C}$ coupling reaction for the production of $\mathrm{C}_{2} \mathrm{H}_{4}$ and $\mathrm{C}_{2} \mathrm{H}_{5} \mathrm{OH}$. The utilization of larger alkali metal cations included in the electrolyte selectively enhanced the adsorption of intermediates with large dipole moments such as ${ }^{*} \mathrm{CO}_{2}$, ${ }^{*} \mathrm{CO}$ and *OCCO. In addition, it was revealed that the field enhancement by tip electrode increased the concentration of surrounding alkali metal cations, dramaticlaly lowering the adsorption free energies of ${ }^{*} \mathrm{COOH}$ and ${ }^{*} \mathrm{CO}$. Furthermore, introducing surface ligand on Au and Ag NPs stabilized " $\mathrm{COOH}$ over " $\mathrm{CO}$, which greatly elevated the selectivity and reduced the overpotential toward $\mathrm{CO}$ production. Also, the single-atom catalysts like $\mathrm{Ni}-\mathrm{N}-\mathrm{C}$ showed the high $\mathrm{CO}$ selectivity which cannot be achieved from the bulk $\mathrm{Ni}$ foil owing to strong " $\mathrm{CO}$ binidng. We believe that this review not only provide deep understandings of $\mathrm{CO}_{2}$ reduction reactions, but also help to create new ideas for future electrocatalyst developments.

\section{Abbreviations}

HER: hydrogen evolution reactions; $\mathrm{CO}_{2} \mathrm{RR}: \mathrm{CO}_{2}$ reduction reactions; DFT: density functional theory; OD-Cu: oxide-derived $\mathrm{Cu} \mathrm{O}_{\text {sub }}$ : subsurface oxygen; APXPS: ambient pressure X-ray photoelectron spectroscopy; EELS: electron energy-loss spectra; $/-\mathrm{CO}_{2}$ : a physisorbed linear $\mathrm{CO}_{2} ; b-\mathrm{CO}_{2}$ : a bent chemisorbed $\mathrm{CO}_{2}$; SIFT-MS: selected-ion flow tube mass spectrometry; GDL: gas diffusion layer; LSV: linear sweep voltammetry; ICP-OES: inductively coupled plasma optical emission spectrometry; M-N-C: metal-incorporated N-doped carbon; P1-AuNP: porphyrin ligand-capped Au NPs; NCNTs: N-doped carbon nanotubes.

\section{Authors' contributions}

CWL, CK and BKM wrote the manuscript. All authors read and approved the final manscript.

\section{Author details \\ ${ }^{1}$ Clean Energy Research Center, Korea Institute Science and Technology, Seoul 02792, Republic of Korea. ${ }^{2}$ Department of Applied Chemistry, Kookmin University, Seoul 02707, Republic of Korea. ${ }^{3}$ Green School, Korea University, Seoul 02841, Republic of Korea.}

\section{Acknowledgements}

Not applicable.

Competing interests

The authors declare that they have no competing interests.

\section{Availability of data and materials}

All data presented in this review article are included in the published article which can be found in the reference list.

\section{Funding}

This work was supported by the program of the Korea Institute of Science and Technology (KIST). This work was also supported by "Next Generation Carbon Upcycling Project" (Project No. 2017M1A2A2046713) through the National Research Foundation (NRF) funded by the Ministry of Science and ICT, Republic of Korea.

\section{Publisher's Note}

Springer Nature remains neutral with regard to jurisdictional claims in published maps and institutional affiliations.

Received: 25 December 2018 Accepted: 22 February 2019

Published online: 12 March 2019

\section{References}

1. M. Meinshausen, N. Meinshausen, W. Hare, S.C.B. Raper, K. Frieler, R. Knutti, D.J. Frame, M.R. Allen, Nature 458, 1158 (2009)

2. C.N. Waters, J. Zalasiewicz, C. Summerhayes, A.D. Barnosky, C. Poirier, A. Gałuszka, A. Cearreta, M. Edgeworth, E.C. Ellis, M. Ellis, C. Jeandel, R. Leinfelder, J.R. McNeill, D.B. de Richter, W. Steffen, J. Syvitski, D. Vidas, M. Wagreich, M. Williams, A. Zhisheng, J. Grinevald, E. Odada, N. Oreskes, A.P. Wolfe, Science 351, aad2622 (2016)

3. D.T. Whipple, P.J.A. Kenis, J. Phys. Chem. Lett. 1, 3451 (2010)

4. K.D. Yang, C.W. Lee, K. Jin, S.W. Im, K.T. Nam, J. Phys. Chem. Lett. 8, 538 (2017)

5. C.W. Lee, K.D. Yang, D.-H. Nam, J.H. Jang, N.H. Cho, S.W. Im, K.T. Nam, Adv Mater. 30, 1704717 (2018)

6. K.P. Kuhl, E.R. Cave, D.N. Abram, T.F. Jaramillo, Energy Environ. Sci. 5, 7050 (2012)

7. K.U.D. Calvinho, A.B. Laursen, K.M.K. Yap, T.A. Goetjen, S. Hwang, N. Murali, B. Mejia-Sosa, A. Lubarski, K.M. Teeluck, E.S. Hall, E. Garfunkel, M. Greenblatt, G.C. Dismukes, Energy Environ. Sci. 11, 2550 (2018)

8. D.L.T. Nguyen, M.S. Jee, D.H. Won, H. Jung, H.-S. Oh, B.K. Min, Y.J. Hwang, A.C.S. Sustain, Chem. Eng. 5, 11377 (2017)

9. F. Marques Mota, D.L.T. Nguyen, J.-E. Lee, H. Piao, J.-H. Choy, Y.J. Hwang, D.H. Kim, ACS Catal. 8, 4364 (2018)

10. K.D. Yang, C.W. Lee, J.H. Jang, T.R. Ha, K.T. Nam, Nanotechnology 28 352001 (2017)

11. K.P. Kuhl, T. Hatsukade, E.R. Cave, D.N. Abram, J. Kibsgaard, T.F. Jaramillo, J. Am. Chem. Soc. 136, 14107 (2014) 
12. H. Kim, H.S. Jeon, M.S. Jee, E.B. Nursanto, J.P. Singh, K. Chae, Y.J. Hwang, B.K. Min, Chemsuschem 9, 2097 (2016)

13. H. Kim, H.S. Park, Y.J. Hwang, B.K. Min, J. Phys. Chem. C 121, 22637 (2017)

14. D.L.T. Nguyen, M.S. Jee, D.H. Won, H.-S. Oh, B.K. Min, Y.J. Hwang, Catal. Commun. 114, 109 (2018)

15. E.B. Nursanto, H.S. Jeon, C. Kim, M.S. Jee, J.H. Koh, Y.J. Hwang, B.K. Min, Catal. Today 260, 107 (2016)

16. Y. Hori, H. Wakebe, T. Tsukamoto, O. Koga, Electrochim. Acta 39, 1833 (1994)

17. C.W. Lee, J.S. Hong, K.D. Yang, K. Jin, J.H. Lee, H.-Y. Ahn, H. Seo, N.-E. Sung, K.T. Nam, ACS Catal. 8, 931 (2018)

18. C.W. Lee, N.H. Cho, K.D. Yang, K.T. Nam, ChemElectroChem 4, 2130 (2017)

19. J.H. Koh, D.H. Won, T. Eom, N.K. Kim, K.D. Jung, H. Kim, Y.J. Hwang, B.K. Min, ACS Catal. 7, 5071 (2017)

20. A. Eilert, F. Cavalca, F.S. Roberts, J. Osterwalder, C. Liu, M. Favaro, E.J. Crumlin, H. Ogasawara, D. Friebel, L.G.M. Pettersson, A. Nilsson, J. Phys. Chem. Lett. 8, 285 (2017)

21. Y.-C. Hsieh, S.D. Senanayake, Y. Zhang, W. Xu, D.E. Polyansky, ACS Catal. 5 $5349(2015)$

22. M. Liu, Y. Pang, B. Zhang, P. De Luna, O. Voznyy, J. Xu, X. Zheng, C.T. Dinh, F. Fan, C. Cao, F.P.G. De Arquer, T.S. Safaei, A. Mepham, A. Klinkova, E. Kumacheva, T. Filleter, D. Sinton, S.O. Kelley, E.H. Sargent, Nature 537, 382 (2016)

23. J. Resasco, L.D. Chen, E. Clark, C. Tsai, C. Hahn, T.F. Jaramillo, K. Chan, A.T. Bell, J. Am. Chem. Soc. 139, 11277 (2017)

24. W. Zhang, Y. Hu, L. Ma, G. Zhu, Y. Wang, X. Xue, R. Chen, S. Yang, Z. Jin, Adv. Sci. 5, 1700275 (2018)

25. T. Takashima, T. Suzuki, H. Irie, J. Photonics Energy 7, 012005 (2016)

26. L.D. Chen, M. Urushihara, K. Chan, J.K. Nørskov, ACS Catal. 6, 7133 (2016)

27. M.R. Singh, E.L. Clark, A.T. Bell, Phys. Chem. Chem. Phys. 17, 18924 (2015)

28. C.W. Lee, N.H. Cho, S.W. Im, M.S. Jee, Y.J. Hwang, B.K. Min, K.T. Nam, J. Mater. Chem. A 6, 14043 (2018)

29. J.T. Feaster, C. Shi, E.R. Cave, T. Hatsukade, D.N. Abram, K.P. Kuhl, C. Hahn, J.K. Nørskov, T.F. Jaramillo, ACS Catal. 7, 4822 (2017)

30. C. Shi, H.A. Hansen, A.C. Lausche, J.K. Nørskov, Phys. Chem. Chem. Phys. 16, 4720 (2014)

31. S.Y. Lee, H. Jung, N.-K. Kim, H.-S. Oh, B.K. Min, Y.J. Hwang, J. Am. Chem. Soc 140, 8681 (2018)

32. C.W. Li, J. Ciston, M.W. Kanan, Nature 508, 504 (2014)

33. P. De Luna, R. Quintero-Bermudez, C.-T. Dinh, M.B. Ross, O.S. Bushuyev, P. Todorović, T. Regier, S.O. Kelley, P. Yang, E.H. Sargent, Nat. Catal. 1, 103 (2018)

34. T.-T. Zhuang, Y. Pang, Z.-Q. Liang, Z. Wang, Y. Li, C.-S. Tan, J. Li, C.T. Dinh, P.D. Luna, P.-L. Hsieh, T. Burdyny, H.-H. Li, M. Liu, Y. Wang, F. Li, A. Proppe, A.
Johnston, D.-H. Nam, Z.-Y. Wu, Y.-R. Zheng, A.H. Ip, H. Tan, L.-J. Chen, S.-H. Yu, S.O. Kelley, D. Sinton, E.H. Sargent, Nat. Catal. 1, 946 (2018)

35. X. Feng, K. Jiang, S. Fan, M.W. Kanan, ACS Cent. Sci. 2, 169 (2016)

36. H. Xiao, W.A. Goddard, T. Cheng, Y. Liu, Proc. Natl. Acad. Sci. U. S. A. 114, 6685 (2017)

37. M. Favaro, H. Xiao, T. Cheng, W.A. Goddard, J. Yano, E.J. Crumlin, Proc. Natl. Acad. Sci. U. S. A. 114, 6706 (2017)

38. L. Mandal, K.R. Yang, M.R. Motapothula, D. Ren, P. Lobaccaro, A. Patra, M. Sherburne, V.S. Batista, B.S. Yeo, J.W. Ager, J. Martin, T. Venkatesan, A.C.S. Appl, Mater. Interfaces 10, 8574 (2018)

39. Y. Lum, J.W. Ager, Angew. Chem. Int. Ed. 57, 551 (2018)

40. C. Liu, M.P. Lourenço, S. Hedström, F. Cavalca, O. Diaz-Morales, H.A. Duarte, A. Nilsson, L.G.M. Pettersson, J. Phys. Chem. C 121, 25010 (2017)

41. F. Cavalca, R. Ferragut, S. Aghion, A. Eilert, O. Diaz-Morales, C. Liu, A.L. Koh, T.W. Hansen, L.G.M. Pettersson, A. Nilsson, J. Phys. Chem. C 121, 25003 (2017)

42. P. Grosse, D. Gao, F. Scholten, I. Sinev, H. Mistry, B. Roldan Cuenya, Angew. Chem. 130, 6300 (2018)

43. M.R. Singh, Y. Kwon, Y. Lum, J.W. Ager, A.T. Bell, J. Am. Chem. Soc. 138, 13006 (2016)

44. C.-T. Dinh, T. Burdyny, M.G. Kibria, A. Seifitokaldani, C.M. Gabardo, F.P. García de Arquer, A. Kiani, J.P. Edwards, P. De Luna, O.S. Bushuyev, C. Zou, R. Quintero-Bermudez, Y. Pang, D. Sinton, E.H. Sargent, Science 360, 783 (2018)

45. K. Jiang, R.B. Sandberg, A.J. Akey, X. Liu, D.C. Bell, J.K. Norskov, K. Chan, H. Wang, Nat. Catal. 1, $111(2018)$

46. C. Kim, H.S. Jeon, T. Eom, M.S. Jee, H. Kim, C.M. Friend, B.K. Min, Y.J. Hwang, J. Am. Chem. Soc. 137, 13844 (2015)

47. C. Kim, T. Eom, M.S. Jee, H. Jung, H. Kim, B.K. Min, Y.J. Hwang, ACS Catal. 7, 779 (2017)

48. Z. Cao, S.B. Zacate, X. Sun, J. Liu, E.M. Hale, W.P. Carson, S.B. Tyndall, J. Xu, X Liu, X. Liu, C. Song, J. Luo, M.-J. Cheng, X. Wen, W. Liu, Angew. Chem. Int. Ed. 57, 12675 (2018)

49. X. Cui, W. Li, P. Ryabchuk, K. Junge, M. Beller, Nat. Catal. 1, 385 (2018)

50. L. Liu, A. Corma, Chem. Rev. 118, 4981 (2018)

51. W. Ju, A. Bagger, G.-P. Hao, A.S. Varela, I. Sinev, V. Bon, B. Roldan Cuenya, S. Kaskel, J. Rossmeisl, P. Strasser, Nat. Commun. 8, 944 (2017)

52. H. Bin Yang, S.-F. Hung, S. Liu, K. Yuan, S. Miao, L. Zhang, X. Huang, H.-Y. Wang, W. Cai, R. Chen, J. Gao, X. Yang, W. Chen, Y. Huang, H.M. Chen, C.M. Li, T. Zhang, B. Liu, Nat. Energy 3, 140 (2018)

53. H. Jung, S.Y. Lee, D.H. Won, K.-J. Kim, S.Y. Chae, H.-S. Oh, B.K. Min, Y.J. Hwang, ChemElectroChem 5, 1615 (2018)

54. P.P. Sharma, J. Wu, R.M. Yadav, M. Liu, C.J. Wright, C.S. Tiwary, B.I. Yakobson, J. Lou, P.M. Ajayan, X.-D. Zhou, Angew. Chem. Int. Ed. 54, 13701 (2015)

\section{Submit your manuscript to a SpringerOpen ${ }^{\circ}$ journal and benefit from:}

- Convenient online submission

- Rigorous peer review

- Open access: articles freely available online

- High visibility within the field

- Retaining the copyright to your article

Submit your next manuscript at $>$ springeropen.com 